\title{
Is it worth reorganising cancer services on the basis of multidisciplinary teams (MDTs)? A systematic review of the objectives and organisation of MDTs and their impact on patient outcomes
}

\author{
Joan Prades ${ }^{\mathrm{a}, *}$, Eline Remue ${ }^{\mathrm{b}}$, Elke van Hoof ${ }^{\mathrm{c}}$, Josep M. Borras ${ }^{\mathrm{a}, \mathrm{d}}$ \\ a Catalan Cancer Plan, Duran i Reynals Hospital, 199-203 Gran Via de l'Hospitalet Av., Hospitalet de Llobregat, 08908 Barcelona, Spain \\ b Belgian Cancer Centre, Scientific Institute of Public Health, Rue Juliette Wytsman 14, 1050 Brussels, Belgium \\ c Experimental and applied psychology, Faculty of educational an psychology sciences, Vrije Universiteit Brusel, Brussels, Belgium \\ d Department of Clinical Sciences, Bellvitge Biomedical Research Institute (IDIBELL), University of Barcelona (UB), Spain
}

\section{A R T I C L E I N F O}

\section{Article history:}

Received 22 October 2013

Received in revised form 8 September 2014

Accepted 9 September 2014

\section{Keywords:}

Interdisciplinary health team

Multidisciplinary communication

Neoplasms

Outcome and process assessment

Clinical conference

\begin{abstract}
A B S T R A C T
Multidisciplinary teams (MDTs) are considered the gold standard of cancer care in many healthcare systems, but a clear definition of their format, scope of practice and operational criteria is still lacking. The aims of this review were to assess the impact of MDTs on patient outcomes in cancer care and identify their objectives, organisation and ability to engage patients in their care. We conducted a systematic review of the literature in the Medline database. Fifty-one peer-reviewed papers were selected from November 2005 to June 2012. MDTs resulted in better clinical and process outcomes for cancer patients, with evidence of improved survival among colorectal, head and neck, breast, oesophageal and lung cancer patients in the study period. Also, it was observed that MDTs have been associated with changes in clinical diagnostic and treatment decision-making with respect to urological, pancreatic, gastro-oesophageal, breast, melanoma, bladder, colorectal, prostate, head and neck and gynaecological cancer. Evidence is consistent in showing positive consequences for patients' management in multiple dimensions, which should encourage the development of structured multidisciplinary care, minimum standards and exchange of best practices.
\end{abstract}

(c) 2014 Elsevier Ireland Ltd. All rights reserved.

\section{Introduction}

Optimal decision-making in the diagnosis, treatment and support of cancer patients is increasingly associated

\footnotetext{
* Correspondence to: Pla Director d'Oncologia, Hospital Duran i Reynals, Av. Gran Via 199-203, Hospitalet de Llobregat, 08908 Barcelona, Spain. Tel.: +34 93 2607417; fax: +34932607316

E-mail addresses: jlprades@iconcologia.net (J. Prades), Eline.Remue@wiv-isp.be (E. Remue), elke.van.hoof@vub.ac.be (E. van Hoof), jmborras@iconcologia.net (J.M. Borras).
}

with multidisciplinary teams (MDTs) [1], an approach validated by experts at the EU level [2], pursued as a key objective in many cancer plans [3], and addressed by the European Commission through the European Partnership for Action Against Cancer (EPAAC) [4,5]. EPAAC addressed multidisciplinary care from a policy perspective in order to define the core elements that all tumour-based MDTs should include [4,5], in part in response to the significant variability observed in the aims, roles and organisational implications of MDTs, as well as differences in performance and access [6,7]. Indeed, the growing number of 
multidisciplinary care studies overlap with evidence on the importance of caseload concentration [8-11], raising questions regarding the best approach to cancer care.

In this context, a review of the published studies on MDT clinical practice and organisation was undertaken for the purpose of assessing the evidence supporting this approach. An initial, comprehensive review of all papers published until 2005 had already been undertaken by Cancer Care Ontario (CCO) [12], a study which gave rise to the creation of a standards document on multidisciplinary cancer conferences. However, while the multidisciplinary approach was documented as influential in changing patient management plans, only limited evidence for the efficacy of multidisciplinary care demonstrated improved clinical outcomes [12]. The aims of this study were to assess the impact of MDTs on patient outcomes in cancer care and identify their objectives, organisation and ability to engage patients in the care process. The present paper sought to update this first review, including all the literature published subsequently up to June 2012.

\section{Materials and methods}

We undertook a literature search in the Medline database for peer-reviewed articles published between the third week of November 2005 and the end of June 2012 that examined multidisciplinary clinical practice and organisation in cancer care. We used the same search terms than Wright et al. did in case of the CCO review: 'tumo $\$ \mathrm{r}$ board\$.mp.'; 'multidisciplinary conference\$.mp.'; 'multidisciplinary clinic\$.mp.'; 'multidisciplinary team\$.mp'; and 'morbidity and mortality conference\$.mp'. The search was limited to papers' titles and abstracts. We adopted a wide conceptual framework of multidisciplinary care by following the consensus definition reached by the healthcare working group of EPAAC: "Multidisciplinary teams (MDTs) are an alliance of all medical and health care professionals related to a specific tumour disease whose approach to cancer care is guided by their willingness to agree on evidence-based clinical decisions and to coordinate the delivery of care at all stages of the process, encouraging patients in turn to take an active role in their care" [13]. Exclusion criteria were as follows: any paper whose main focus was not the MDT decision-making process; any paper in which the MDT, at least, did not include the medical specialties necessary for planning treatment; any paper focusing on paediatric patients; any review, editorial, comment, etc.; and any paper written in a language other than English. A flow chart listing all the papers retrieved and selected is shown in Fig. 1.

The selection of papers was conducted in four steps by two reviewers working independently (JP, ER). In the event of disagreement, a third reader reviewed the paper and made a final decision after careful discussion with the team, with the aim of reaching a consensus. Two types of original papers were included: the first comprised publications relating to the impact of MDT patient management on clinical and process outcomes (these typically compared multidisciplinary interventions to one-on-one settings, or before-and-after MDT performance); the second type included papers which contributed to improving cancer care. The latter was divided in three subsections: (1) MDTs' mandate, (2) organisation and (3) patient engagement. With regard to the organisation, the following issues were included: format, team members, roles and responsibilities, data-management and support. Unlike the CCO review, and in recognition of its importance in the reviewed papers, "patient engagement" was also included as a theme. We opted for a narrative review because of the extreme difficulty entailed in conducting a quantitative assessment of the papers included, owing to the different end-points, populations and definitions of the variables used.

\section{Results}

Fifty-one papers were selected for inclusion in this review (see Fig. 1). The main characteristics of the papers included in the review are also presented (see Tables 1 and 2).

\subsection{Impact on patient outcomes}

Twenty-nine studies assessed the impact of MDT patient management on outcomes by linking outcome data to the introduction or presence of MDTs in different settings [14-42]. All studies concluded that a multidisciplinary setting resulted in improved patient outcomes in terms of diagnosis and/or treatment planning [14-16,18-22,25-29,31-33,35-37,40,42], improvements in survival $[15,17,21,23,28-30,36,39,41]$, patient satisfaction $[24,31,38]$ and clinician satisfaction as a consequence of teamwork communication and cooperation [15,34]. Evidence of improved survival was found for colorectal $[15,17,28,36]$, head and neck [29,41], breast [39], oesophageal [21] and lung [30] cancer. MDTs contributed to changing clinical diagnostic and treatment decisionmaking with respect to urological [14], pancreatic [16], gastro-oesophageal [19,35], breast [20], melanoma [25], bladder [27], colorectal [22], prostate [42], head and neck [33] and gynaecological [35] cancer patients. The other 22 studies focused on the structure and functions related to MDT organisation by identifying how the format, data management and professional roles of MDTs impacted positively on care coordination for professionals and patients (Table 2).

\subsection{MDT goals and scope of practice}

MDTs mandate. The studies documented two motivating principles: firstly, MDTs ensure more appropriate treatment through a preoperative review of imaging and pathology results $[19,20,22,25,26,40,42]$; and secondly, a multidisciplinary approach guarantees the most up-todate treatment for all cancer patients seen at the facility or discussed online [16,18,21,23,32,33,35,38-41,53]. Other clinical-based goals included improving patients' quality of life $[24,32,42,53-55]$ and setting up a structured followup care plan [53,59-61]. Concerning team performance, the main goals cited were improving coordination and continuity of care by reducing time from diagnosis to treatment (or access to MDTs) [30,35,38,58]; achieving early and appropriate referral patterns [17,26,32,45,49,51]; and 
Table 1

Studies which demonstrated improved outcomes with multidisciplinary patient management.

\begin{tabular}{|c|c|c|c|}
\hline Study & Type of study & Endpoints assessed & Outcome \\
\hline Kurpad et al. [14] & $\begin{array}{l}\text { Prospective cohort study of patients with } \\
\text { urological malignancies (2007-2008) }\end{array}$ & $\begin{array}{l}\text { Effect of MTM on diagnosis and treatment } \\
\text { decisions }\end{array}$ & $\begin{array}{l}38 \% \text { of patients had a change in diagnosis or } \\
\text { treatment decisions }\end{array}$ \\
\hline Segelman et al. [15] & $\begin{array}{l}\text { Retrospective cohort study of county cancer } \\
\text { registry data (1995-2004) }\end{array}$ & $\begin{array}{l}\text { MDT assessment and treatment in patients with } \\
\text { stage IV CRC }\end{array}$ & $\begin{array}{l}\text { Metastasis surgery was more common among } \\
\text { patients who were assessed than those who were } \\
\text { not assessed by an MDT }(6.9 \% \text { vs. } 1.2 \% \text {, } \\
p<0.001) 37 \% 5 \text {-year survival among CRC patients } \\
\text { selected vs. } 2 \% \text { among those not selected for } \\
\text { metastasis surgery }(p<0.001)\end{array}$ \\
\hline Pawlik et al. [16] & $\begin{array}{l}\text { Prospective cohort study of pancreatic cancer } \\
\text { patients (2006-2007) }\end{array}$ & $\begin{array}{l}\text { Clinical recommendations made with or without a } \\
\text { 'single-day' MDC assessment for pancreatic cancer } \\
\text { patients }\end{array}$ & $\begin{array}{l}23.6 \% \text { of patients experienced a change with } \\
\text { respect to their previous recommended } \\
\text { therapeutic planIncreased patient access to clinical } \\
\text { trialsIncreased tumour-registry enrolment (from } \\
49.2 \% \text { to } 77.8 \% \text { ) }\end{array}$ \\
\hline Lordan et al. [17] & $\begin{array}{l}\text { Prospective study (1996-2006) comparing CRC } \\
\text { patients referred to an MD specialist hepatobiliary } \\
\text { unit (with liver surgeon) vs. local CRC MDTs }\end{array}$ & $\begin{array}{l}\text { 1-, 3- and 5-year survival for patients who develop } \\
\text { colorectal liver metastases }\end{array}$ & $\begin{array}{l}\text { Patients referred to the MD unit had } 1-, 3 \text { - and } \\
5 \text {-year survival rates of } 89.6 \%, 67.5 \% \text { and } 49.9 \% \text { vs. } \\
90.3 \%, 54.1 \% \text { and } 43.3 \% \text { respectively among those } \\
\text { referred to local MDTs }\end{array}$ \\
\hline Chekerov et al. [18] & $\begin{array}{l}\text { Questionnaire to participants of an online tumour } \\
\text { conference for complex gynaecological cases }\end{array}$ & $\begin{array}{l}\text { Physicians acceptance and satisfaction with online } \\
\text { national TB }\end{array}$ & $\begin{array}{l}78 \% \text { of recommendations were accepted and } \\
\text { implemented } 88 \% \text { of participants considered there } \\
\text { was benefit for their clinical practice }\end{array}$ \\
\hline Davies et al. [19] & Prospective cohort study (1997-2002) & $\begin{array}{l}\text { Staging accuracy and treatment selection of } \\
\text { gastro-oesophageal patients }\end{array}$ & $\begin{array}{l}\text { MDT staging and assessment of nodal disease were } \\
\text { more accurate than each individual staging } \\
\text { modality for T and } \mathrm{N} \text { staging }\end{array}$ \\
\hline Newman et al. [20] & $\begin{array}{l}\text { Retrospective review of medical records } \\
(2000-2001)\end{array}$ & $\begin{array}{l}\text { Effect of breast TB recommendations on patients } \\
\text { looking for a second opinion }\end{array}$ & $\begin{array}{l}52 \% \text { of patients had changes in recommendations } \\
\text { for surgical management }\end{array}$ \\
\hline Stephens et al. [21] & $\begin{array}{l}\text { Retrospective case-control study of patients } \\
\text { managed by an MDT (1998-2003) or by surgeons } \\
\text { working independently (1991-1997) }\end{array}$ & Outcomes after surgery for oesophageal cancer & $\begin{array}{l}\text { Lower operative mortality ( } 5.7 \% \text { vs. } 26 \% \text {, } \\
p=0.0004 \text { ) and higher survival ( } 52 \% \text { vs. } 10 \% \text {, } \\
p=0.0001 \text { ) among MDT patients than those } \\
\text { managed by general surgeons }\end{array}$ \\
\hline
\end{tabular}

Burton et al. [22]

Retrospective cohort study of rectal cancer patients (1999-2002), comparing CRM+ ve rates of patients discussed vs. those not discussed at MTM Nguyen et al. [23] Retrospective cohort study (1997-2006) of locally advanced head and neck cancer patients

Impact of preoperative MRI-based MDT discussion on treatment strategy

Survival of postoperative radiation and chemoradiation groups of patients, based on TB recommendations

Ibrahim et al. [24] Observational retrospective study (2005-2008) of Patient satisfaction an osteo-oncology centre and use of questionnaires

Retrospective cohort study of melanoma cance patients (2006-2009)
Diagnosis and staging review of patients referred from an outside facility and impact on surgical recommendations
MDT discussion of MRI resulted in CRM+ in 1\% of patients ( 1 out of 116 ) vs. $26 \%$ of those (16 out of 62) without MDT discussion

TB patient survival rate was comparable to those reported by RCT

$75 \%$ of patients were very satisfied with the service provided $74 \%$ of patients were not disturbed by MD visits

$3 \%$ of invasive thin melanoma patients and $6 \%$ of in situ melanoma patients had changes in interpretation $26 \%$ of ITM patients were restaged ( $13 \%$ upstaged, and $13 \%$ downstaged) $12 \%$ of patients ( $7 \%$, smaller excision margin; $5 \%$, wider margin) had changes with respect to primary lesion in recommended surgical excision margin 
Table 1

(Continued)

\section{Study}

Sooriakumaran et al. [26]

ype of study

Retrospective review of urological patients (2007)

Prospective study of bone metastases patients

Pituskin et al. [27]

Du et al. [28]

Friedland et al. [29]

Bydder et al. [30

Caudron et al. [31]

Boxer et al. [32]

Wheless et al. [33]

Field et al. [34]

Freeman et al. [35] referred to an outpatient palliative RT clinic (2007)

Retrospective review of rectal cancer patients (2001-2005), comparing patients receiving MDT treatment vs. those receiving direct surgery

Retrospective review of hospital registry database and head and neck cancer clinic (1996-2008), comparing outcomes of patients managed by an MDT and individual disciplines

Prospective study of hospital cancer registry database (2006), comparing lung cancer patients discussed vs. those not discussed at MTMs Retrospective study of skin cancer patients (2006-2007)

Retrospective review of regional cancer registry and MDT database (2005-2008), comparing lung cancer patients presented vs. those not presented at MTM

Prospective study of head and neck cancer patient (2009-2010), comparing benign and malignant cohorts

Survey of neuro-oncology MTM attendees (2009)

Retrospective cohort study of oesophageal cancer patients, comparing patients treated before and after the initiation of the MD conference (2001-2007)
Endpoints assessed

Impact on management decisions by a central MD with respect to referred cases from a local MDT

Impact of a systematic multidisciplinary screening and non-physician assessment on

recommendations for patient management Effect of MDT discussion on treatment selection and outcomes

Survival of head and neck cancer patients and clinical management factors

Impact on treatment and survival of patients with noperable NSCLC

Evaluation of MTM functioning and

decision-making process

mpact of MDT discussion on patterns of care survival and quality of life

Effect of TB discussion on diagnosis, stage and reatment plan decisions

Clinician satisfaction with MTMs and documentation procedures

mpact of the MD thoracic malignancy conference in patient care and adherence to NCCN guidelines
Outcome

$1 \%$ of bladder cancer patients had their treatmen plan changed $9 \%$ of prostate cancer patients were excluded from/recommended for clinical trialsOne kidney cancer patient had his treatment-plan decision changed

Symptom improvement in pain, tiredness, depression, anxiety, drowsiness and overall wellbeing (reported at 4 weeks)

$37.1 \%$ sphincter preservation in the MDT vs. $13.5 \%$ in the non-MDT subgroup $(p<0.005) 77.2 \% 5$-year survival rate in the MDT group vs. $69.7 \%$ in the non-MDT group $(p=0.049)$

Higher survival for MDT patients compared to individually managed patients $(\mathrm{HR}=0.69 ; 95 \%$ $\mathrm{CI}=0.51-0.88$ at 5 -year survival for stage-IV patients)More synchronous chemotherapy and radiotherapy in MDT patients $(p=0.004)$

$33 \%$ 1-year survival among NSCLC patients discussed vs. $18 \%$ among those not discussed $(p=0.0478)$

$88 \%$ of MTM recommendations were

implemented $49.4 \%$ of patients attended their MTM MDT patients (some sub-groups) received better treatment (access to radiotherapy, chemotherapy and palliative care)

$27 \%$ of all patients had some change in diagnosis and treatment $65 \%$ of the malignant cohort patient experienced the addition of a treatment modality $(p=0.0212)$

$100 \%$ felt that the MTM and its documentation procedures were very or extremely important $94 \%$ felt that the MTM was effective in the documentation and communication of plans $97 \%$ of MD vs. $67 \%$ of non-MD patients received complete staging evaluation $(p<0.0001) 98 \%$ of MD vs. $72 \%$ of non-MD patients had multidisciplinary evaluation before treatment $(p<0.0001)$ Adherence to NCCN guidelines was $98 \%$ in MD and $83 \%$ in non-MD patients $(p<0.0001)$ Mean days from diagnosis to treatment were 16 for MD vs. 27 for non-MD patients $(p<0.0001)$ 
Table 1

(Continued)

\begin{tabular}{|c|c|c|c|}
\hline Study & Type of study & Endpoints assessed & Outcome \\
\hline Palmer et al. [36] & $\begin{array}{l}\text { Retrospective cohort study of population-based } \\
\text { registry (1995-2005), comparing tumour staging } \\
\text { and outcomes of locally advanced rectal cancer } \\
\text { patients with or without MDT assessment }\end{array}$ & $\begin{array}{l}\text { Effect of MDT assessment in preoperative local and } \\
\text { distant staging on management and outcome }\end{array}$ & $\begin{array}{l}\text { Incidence of R0 resection was } 52 \% \text { in MDT vs. } 43 \% \\
\text { in non-MDT patients ( } p<0.001 \text { )Local tumour } \\
\text { control was 57\% in MDT vs. } 36 \% \text { in non-MDT } \\
\text { patients ( } p<0.001 \text { )Five-year survival was 30\% } \\
\text { among MDT vs. } 28 \% \text { among non-MDT patients }\end{array}$ \\
\hline Greer et al. [37] & $\begin{array}{l}\text { Retrospective study of gynaecological cancer } \\
\text { patients (2004-2006) }\end{array}$ & Impact of $\mathrm{TB}$ on patient management & $\begin{array}{l}27 \% \text { of patients had changes in diagnosis, a } \\
\text { discrepancy that altered their treatment plan by } \\
74 \%\end{array}$ \\
\hline Bjegovich-Weidman et al. [38] & $\begin{array}{l}\text { Retrospective and descriptive study of a lung } \\
\text { cancer MDC }\end{array}$ & Time to treatment & $\begin{array}{l}\text { Time from diagnosis (biopsy) to treatment was } \\
\text { reduced to a mean of } 18 \mathrm{vs.} 24 \text { days before MDC } \\
\text { implementation }\end{array}$ \\
\hline Kesson et al. [39] & $\begin{array}{l}\text { Retrospective, comparative, non-randomised, } \\
\text { interventional cohort study of breast cancer } \\
\text { patients (1990-2000) }\end{array}$ & $\begin{array}{l}\text { Cancer-specific mortality and all-cause mortality } \\
\text { between two neighbouring areas before and after } \\
\text { the introduction of MDTs }\end{array}$ & $\begin{array}{l}\text { At } 5 \text { years, breast cancer mortality was } 18 \% \text { lower } \\
\text { and all-cause mortality was } 11 \% \text { lower in the } \\
\text { intervention area than in the non-intervention area }\end{array}$ \\
\hline Levine et al. [40] & $\begin{array}{l}\text { Prospective study of CRC patients ( } 2008-2009 \text { ), } \\
\text { comparing patients referred to the MDC vs. } \\
\text { patients managed outside }\end{array}$ & $\begin{array}{l}\text { Comprehensiveness of the preoperative } \\
\text { evaluation, and access to multimodal care }\end{array}$ & $\begin{array}{l}\text { Complete pre-operative evaluation in MDC } \\
\text { patients was } 85 \% \text { vs. } 23 \% \text { in the control group } \\
(p<0.0001) 62.5 \% \text { of MDC patients vs. } 41.5 \% \text { of } \\
\text { control group patients had peri-operative } \\
\text { treatment ( } p=0.02) 76 \% \text { of MDC rectal cancer } \\
\text { patients vs. } 20 \% \text { of control group patients } \\
\text { underwent neoadjuvant therapy }(p<0.0001)\end{array}$ \\
\hline Wang et al. [41] & $\begin{array}{l}\text { Retrospective, longitudinal cohort study of } \\
\text { national health database (2004-2008), comparing } \\
\text { participation/non-participation of patients in MDT } \\
\text { care }\end{array}$ & $\begin{array}{l}\text { Survival and effects of MDT care on oral cavity } \\
\text { cancer patients }\end{array}$ & $\begin{array}{l}\text { Higher survival among MDT-participant vs. } \\
\text { non-participant patients (HR=0.84; } 95 \% \\
\mathrm{CI}=0.78-0.90 \text { at } 5 \text {-year survival for MDT patients) }\end{array}$ \\
\hline Korman et al. [42] & $\begin{array}{l}\text { Retrospective cohort study of MDC database and } \\
\text { hospital registry (2006-2011), comparing patients } \\
\text { treated before and after the initiation of an MDC }\end{array}$ & $\begin{array}{l}\text { Impact on prostate and genitourinary patient } \\
\text { treatment decisions and adherence to NCCN } \\
\text { guidelines }\end{array}$ & $\begin{array}{l}41 \% \text { of low-risk MDC vs. } 27 \% \text { of non-MDC patients } \\
\text { chose external beam radiation therapy } \\
(p=0.02) 30 \% \text { of MDC vs. } 44 \% \text { of non-MDC patients } \\
\text { chose prostatectomy ( } p=0.03) 14 \% \text { of MDC vs. } 61 \% \\
\text { of non-MDC patients chose active surveillance } \\
(p=0.02 \text { )Adherence to NCCN guidelines was } 90 \% \\
\text { among intermediate-risk MDC patients vs. } 76 \% \\
\text { among non-MDC patients ( } p=0.01 \text { ) }\end{array}$ \\
\hline
\end{tabular}

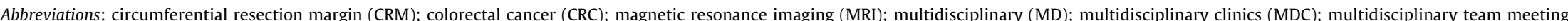

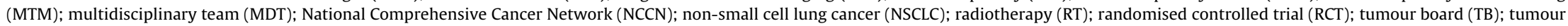
node metastasis (TNM).

abase (2004-2008), comparing

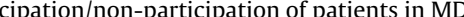

Retrospective cohort study of MDC database and hospital registry (2006-2011), comparing patients treatment decisions and adherence to NCCN guidelines 


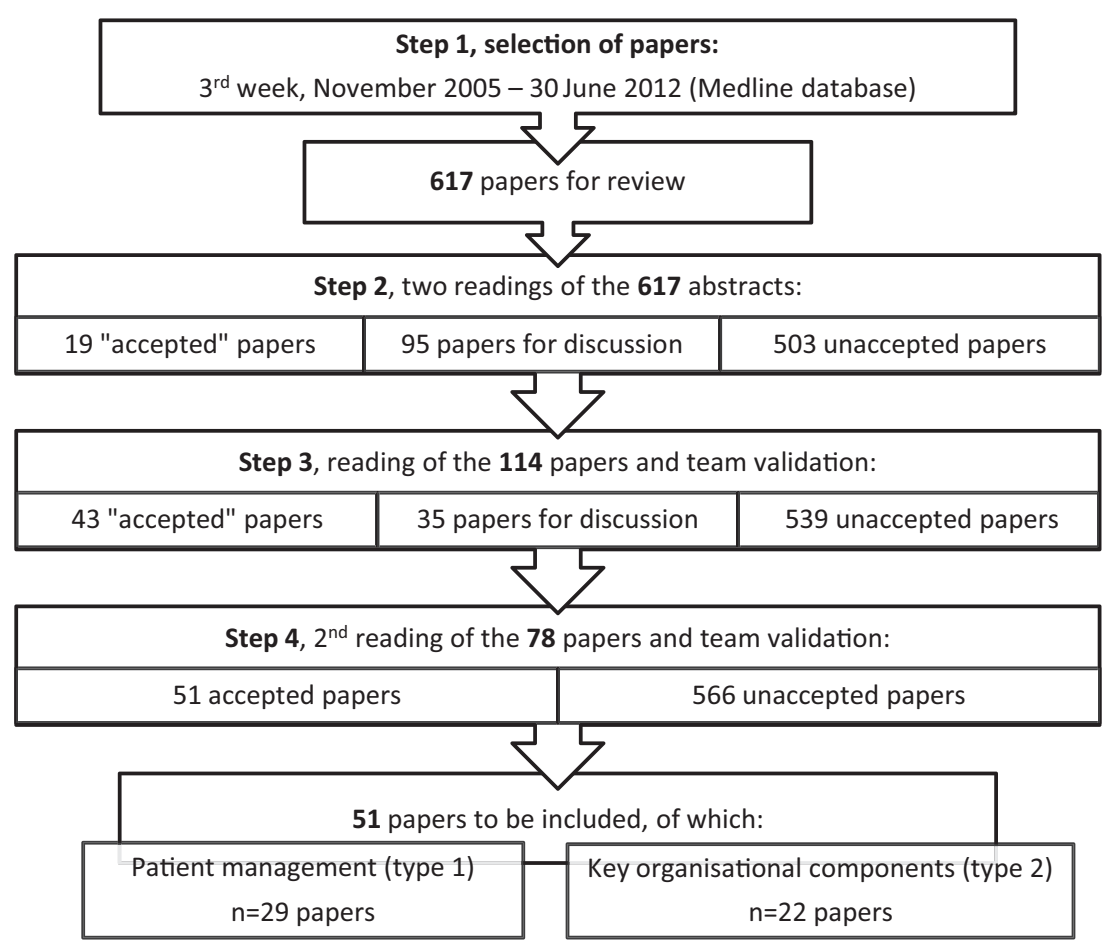

Fig. 1. Flow chart showing the selection of papers.

maintaining a commitment to research and clinical trials $[15,16,18,26,38,43,44,56,57]$. Secondary objectives also included providing a teaching environment for healthcare professionals and junior doctors [18,20,24,30,32,34,54]; acting as a quality improvement group [22,34,50,54]; and increasing enrolment in the tumour registry [16].

\subsection{MDT organisation}

Format. Even though MDT meetings were usually held once a week, different organisational practices were used depending on the format of the MDT (see Table 2). Essentially, there were three types of formats in clinical practice. Firstly, there were meetings, which lasted anywhere from $30 \mathrm{~min}$ to $2 \mathrm{~h}$ and included either all or a selection of diagnosed and/or referred patients; patients were selected by the specialist in charge based on the case's level of complexity or the wide range of therapeutic possibilities, prearranged team criteria, or triage by the clinical coordinator $[27,30,32-34,46,48,50]$. A second MDT format was the multidisciplinary clinic, where patients were not only seen but also simultaneously examined $[16,38,40,53,54]$ or remotely coordinated by all board members [42]. Finally, online conferences made use of specific web-based software to organise and conduct online tumour board meetings among clinicians within a given hospital [16] or nationwide [18].

Meeting presentations involved prospective reviews of new and recurrent cases, previously reviewed cases requiring additional follow-up [29,33], and second opinions, which were seen as useful for patients and physicians when faced with difficult treatment decisions $[18,20,38]$.
Attendance at meetings, whatever their format, varied significantly.

Team members. MDT membership and attendance at meetings varied according to hospital size and medical specialty. Other important predictors were cancer type, format of the delivery setting, and perceived efficiency of the meeting performance $[45,50-52,62]$. Several papers differentiated team composition by identifying three levels of involvement, i.e., "core", “allied" (or "extended") and "expert support" membership. Core and allied members included radiologists, pathologists, surgeons, radiation and medical oncologists, oncology nurses, palliative care physicians, head and neck specialists, nuclear medicine specialists, respiratory disease physicians, gastrointestinal disease physicians and anaesthesiologists, some of whom were frequently sub-specialised by tumour site $[20,29,30,32-34,42,43,45,52,53]$. The support members included psychologists, nutritionists, dieticians, plastic surgeons, speech therapists, patients' GPs, physiotherapists, practitioners of complementary medicine, orthopaedic specialists, medical physicists, odontologists, faith counsellors, biologists, data managers, genetic counsellors, hospital pharmacists, social workers and occupational therapists $[24,27,40,45,49,54,55]$.

Roles and responsibilities. A number of studies examined the role of a designated coordinator or chairperson in ensuring the smooth functioning of the MDT setting. The different scopes of coordination and the need to adapt to particular practice contexts implied the problem of finding 'equivalents' of the role and defining consistent profiles. Nonetheless, an analysis of the studies allowed the differentiation between 'inward' responsibilities (MDT organisation and efficient direction) and 


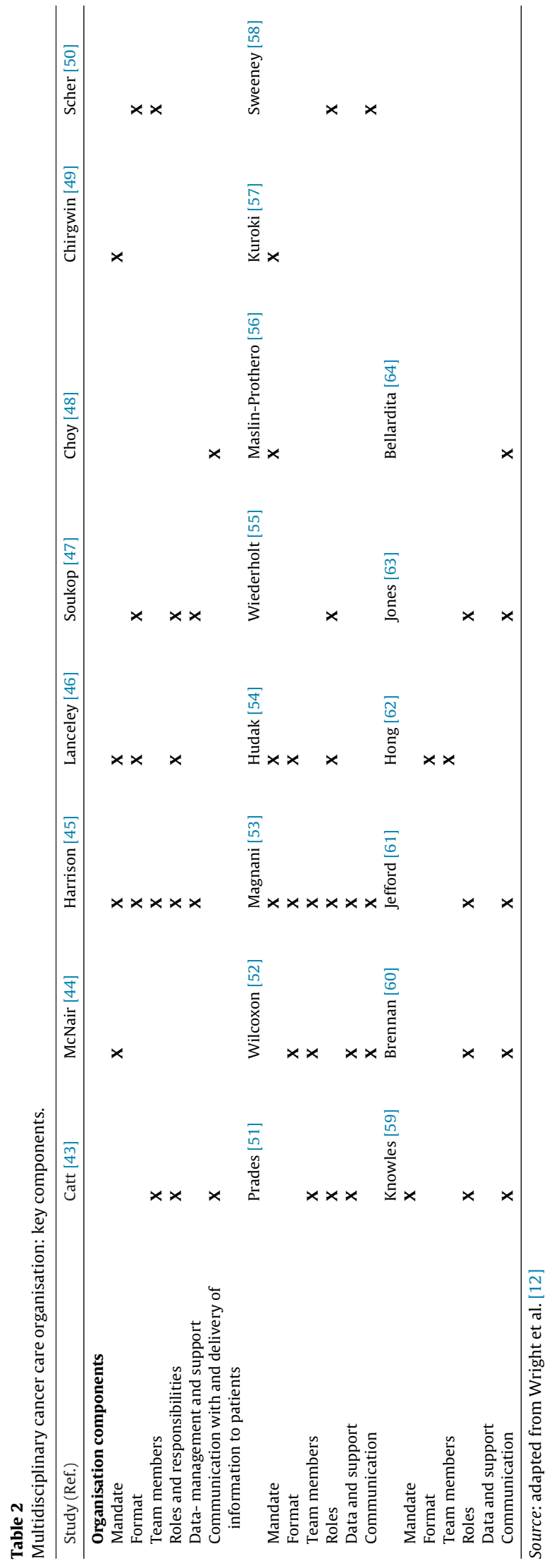

'outward' responsibilities (clinical management of the care plan). Whereas inward responsibilities consisted of scheduling agendas for meetings, drawing up the list of patients to be discussed, ensuring that all necessary tests were obtained and available in advance of the discussion, and recording the MDT decisions and rationales agreed [34,38,42,45,46], outward tasks entailed communicating decisions to patients/families, GPs, providers and referring physicians, as well as coordinating outpatient visits and referrals from satellite centres, and facilitating the link to research either directly or by improving liaison with the clinical trial coordinator $[24,32,34,38,42,43,53,54]$. Other studies documented the role of clinical nurses in guiding the patient through the care pathway or assuming the task of coordinating the follow-up [29,40,42,43,45,47,53-55,58-61,63]. The main responsibilities fulfilled by nurses were: providing psychosocial support and education to the patient; managing treatment-related toxicities and side-effects; coordinating services (diagnostic and treatment agenda); facilitating liaison with external support services; managing patient transition across the cancer network; and acting as a focus of communication between team and patient.

Data management and support. The use of information technology (IT) was commonly described as a useful way of sharing patient details and providing documentation, such as the minutes of an MDT meeting aimed at setting up a prospective clinical database. Several studies showed how hospital intranets allowed for a password-protected view of virtual MDT meeting minutes, which were embedded or developed within the same system. Repeated reference was made to the need to clarify how and why final decisions were reached. Some papers mentioned the importance of available facilities, such as a meeting room with good acoustics, computer access at all sites within a cancer network, and a telephone number to provide centralised access to patients managed by the case nurse manager. The decision to overcome logistics-related barriers through the medium of online video-conferences and the use of IT to share radiology and histopathology images, were also described and examined. Finally, the need to support MDTs' clerical and general administrative activity was highlighted $[18,30,32,34,42,45,50,52]$.

\subsection{MDT patient engagement}

Communication with and delivery of information to patients. A number of studies reflected a desire to involve patients actively in their care and promote greater understanding of the specific collaborative MDT intervention. Indeed, some expressly mentioned that the MDT rationale had been explained to the patient $[23,24]$. Treatment, toxicities, side effects, complications and information on second- and third-line treatments after recurrent disease were variously reported as having been discussed with patients before making decisions, sometimes by using written materials or by providing access to psychologists or social workers $[18,20,23,38,42,52,53,56,58,59,61,64]$. A number of papers identified the need to take into account patients' physical and psychological comorbidities when making clinical decisions; furthermore, they noted that 
special attention should be paid to provide the same clinical message and bridging gaps between teams and patients, as well as clearly setting out how to deal with the complexities of the health care system $[43,44,53,54,56,60,63]$. Other studies addressed issues such as the patient-doctor relationship within a multidisciplinary setting, the impact of pre-existing knowledge of the patient in MDT discussions, patient attendance at and involvement in MDT meetings, and the way in which the patients are approached to participate in clinical trials $[46,48,56,64]$. The need to facilitate access to community resources, namely, patient support groups, libraries and volunteers, was also described $[54,55,58]$.

\section{Discussion}

This review showed that MDTs resulted in better clinical and process outcomes for cancer patients, with evidence of improved survival among colorectal [15,17,28,36], head and neck [29,41], breast [39], oesophageal [21] and lung [30] cancer patients across the study period (2005-2012). Mention should likewise be made of the contribution made by MDTs in changing clinical diagnostic and treatment decision-making with respect to urological [14], pancreatic [16], gastro-oesophageal [19,35], breast [20], melanoma [25], bladder [27], colorectal [22], prostate [42], head and neck [33] and gynaecological [35] cancer patients. The paper from Kesson et al. merits a specific mention since it used an interrupted time series analysis in order to assess the impact of MDTs in one intervention area, demonstrating a significant improvement in survival [39].

A number of studies also showed the growing importance of organisation in ensuring smooth teamwork. These papers showed that collaboration transcends the setting of individual meetings held to make key clinical decisions. Instead, such an organisational mechanism-tumour board, cancer conference or other-evolves into the epicentre of a streamlined, comprehensive management approach made up of different components and interfaces, from diagnosis to treatment and follow-up. For example, MDT members undertook the role of 'agent' in explaining to patients the possibility of entering clinical trials in order to improve recruitment [43,44,56,57]; participated in tumour-based collaboration with psycho-oncologists and palliative care teams to improve care processes for advanced cancer patients [49]; and empowered nurse case managers to ensure continuity of care for patients within a network [58], coordinating follow-up programmes [59], or managing follow-up with other healthcare providers $[55,60,61]$. These examples involved an extension of specialised access and team control that goes beyond the treatment stage. It is worth highlighting the amount of attention paid to maintaining consistent communication and delivery of information between the team and the patient. Explanations for this included the need to improve management of therapy-induced adverse effects and, in a broad sense, quality-of-life aspects, both of which call for patients and families to play an active role $[16,22,33,48,53,54]$.

Two prominent MDT organisational approaches emerged in our analysis: on the one hand, meetings or conferences in Europe, Australia and Canada, and on the other, clinics in the USA. The former entails some degree of clinical service cooperation or unit integration in a new scenario, in contrast to the traditionally fragmented one that prevailed before the introduction of the MDT. The latter, often called 'one-stop care', generally seeks to concentrate team efforts at a specific moment in time, usually through patient examinations by all board members, subsequent group discussion and then proposal of a treatment plan. One leading argument put forward to support this approach in the USA is that it prevents outward migration to competing providers [38].

Nonetheless, organisational variables, such as team composition, have been shown to be associated with the quality of clinical care [65]. Although several papers reflected that MDTs worked in accordance with a regional or national policy strategy [20-22,26,29,31,34,41,44-52] (with some exceptions $[16,69,70]$ ), teamwork was rarely framed by specific policy guidance. Its absence led to some problems, for instance, emotional exhaustion among team leaders and clinical nurses owing to the lack of defined professional roles and team training $[43,63]$. As Ruhstaller et al. proposed, efforts should be made to develop the 'theoretical MDT model' in order to avoid situations such as the involvement of professionals who are unfamiliar with patients in decision-making that affects them [7].

Several questions have also been raised regarding the quality of the evidence. Some authors discussed the lack of rigorous methodology, design and clear definitions of multidisciplinary cancer care models in studies aimed at ascertaining the effectiveness or overall impact of teamwork on outcomes or process measures [66,67]. It has to be said that, when it comes to inferring a direct causal relationship between interventions that depend on an MDT context and clinical outcomes, the evidence is limited. Indeed, most of the initial papers were based on observational retrospective data and thus afford only weak support for the hypothesis from a methodological point of view. Yet, this review found a significant number of prospective studies which report clinical benefits based on changes in diagnostic and treatment decisions, and so provide better evidence of the effectiveness of MDTs [14,16,17,19,27,30,33,40].

There were a number of differences with respect to the systematic review conducted by Wright et al. for the period 1960-2005. Firstly, there was a wide variation in the types of tumours studied (e.g., bone metastasis, skin or brain cancer) and a marked increase in papers discussing colorectal, head and neck, and prostate and genitourinary neoplasms. This can be explained by the increasing number of different therapeutic options at several tumour sites, some of which rely to a major degree on the involvement of different medical specialties, such as preoperative radiochemotherapy for rectal cancer [68]. Also, whereas the papers' main clinical focus was the therapeutic decision-making context, the role of MDTs tended to expand and embrace the whole process of care, from patient diagnosis to follow-up (see Table 3). This, together with the presence of studies showing enhanced access to palliative care teams and clinical trial coordinators, is an indicator of the wider perspective taken by research with respect to the impact of MDTs. In any case, findings yielded from this research strengthen 
Table 3

Clinical focus ${ }^{\mathrm{a}}$ of the selected papers $(n=51)$.

\begin{tabular}{ll}
\hline Clinical focus & No. of studies \\
\hline Treatment & 18 \\
Diagnosis and treatment & 14 \\
Diagnosis, treatment and follow-up & 7 \\
Follow-up & 3 \\
Access to clinical trials & 3 \\
Diagnosis (staging) & 2 \\
Palliative care & 2 \\
Treatment and follow-up & 1 \\
Treatment and palliative care & 1
\end{tabular}

$\bar{a}$ Note: regardless of specific mandate (patient survival, quality of care, etc.).

the evidence base gathered from Wright et al.'s review and provide further support for the MDT approach to cancer care.

The delivery of cancer care is constantly challenged by changes in the supply side. Elements such as the increased complexity of multi-modal treatments and the emergence of new areas of cancer care intervention (e.g., genetic counselling, oncogeriatrics, survivorship, etc.) lead to a broader remit, bigger MDTs consisting of different levels of professional involvement, and an increased need for an active chair. Moreover, it is not rare for expert MDTs to work at different levels of clinical complexity, either embedded in cancer networks or fostering inter-hospital cooperation at a clinical level. Since professionals, rather than managers, are the operational nodes arranging the daily life of these connections, their ability to cooperate as a multidisciplinary team, in their own hospital, is critical.

Thus, it seems essential to formalise the necessary organisational adjustments, identifying the tumour-based MDTs as a specific area for clinical management. This approach implies shaping health services so that clinical departments' interest and pathology programmes coalesce in a matrix pattern. An effective multidisciplinary model of cooperation is enabled when control over pathology-related decision-making processes is decentralised towards MDTs. Regardless of how they are integrated into cancer services (through the establishment of multidisciplinary clinics, meetings, etc.), a reorganisation following such a path requires a definition of MDT boundaries and scope of practice, promoting adherence to the coordination mechanisms put in place, providing administrative support, and promoting team roles and distributed leadership compatible with traditional hierarchies. Policymakers and hospital managers may greatly contribute to the effectiveness and stability of this system by articulating these operating conditions, stimulating clinical accountability for the decisions made and ensuring liability on patients' clinical pathway, including in communication with them [71].

Cancer policy and health system funding are focused on structures, not on specific organisational approaches. However, the starting point should be recognising that hospital performance in cancer care is increasingly dependent on more complex and multidisciplinary decision-making processes and models of care, in which crosscutting roles, sub-specialised teams and clinical networks are of central importance [72].
As health systems increasingly pursue patient-centred approaches that treat people, rather than diseases, new dimensions of care have emerged as critical, including psychosocial aspects, quality of life, patients' rights and empowerment, comorbidities and survivorship. These new complexities introduce challenges in communication, coordination and organisation, but they also promise a more holistic care model and ultimately, better patient outcomes [13]. MDTs are the cornerstone of such an approach and as such, they merit careful study in order to optimise their operation.

In order to better assess the results of our study, some limitations should be taken into account. First of all, the review of the literature was necessarily narrative, since a quantitative impact analysis was not considered feasible in view of the diversity of end points, definitions of variables and health care contexts. Grey literature was not included and thus no mention was made of the situation of multidisciplinary care reflected in reports and other sources. Lastly, the conceptual variability in the use of terms, such as multidisciplinary management, multidisciplinary protocols and clinical guidelines, negatively affected the literature search and increased the efforts required to include all the papers published under an umbrella of similar terminology. There is a clear need to reach some consensus about the terminology employed and what it is implied by each concept used to describe clinical practice.

\section{Conclusions}

Advantages in the adoption of a multidisciplinary approach do not result inevitably from the will to implement it on the basis of a policy decision [43]. Thus, specific guidance, team training and investment of resources-along with further research-are needed. In the case of resources, our research uncovered a growing gap among MDTs with respect to two functional dimensions. On the one hand, while some teams favour the celebration of physical meetings, others show a rapid adoption of IT for data-management and communication, a potential enabler to overcome logistical barriers in the context of a network of hospitals. On the other hand, teamwork seems to be especially reinforced when clinical data recording can be evaluated in-house or linked to cancer registries or administrative databases, which is usually not the case. Finally, although many papers set up clear roles for MDT membership by identifying "core" and "alliance" members, most papers were not clear about whether all patients should benefit from multidisciplinary management, or just some.

In brief, the rationale behind the more comprehensive structuring of teamwork in cancer care goes beyond eventual clinical outcomes and embraces the process of care as a whole. At the same time, however, analysing the outcomes demonstrates that the lack of clear, uniform operational criteria when it comes to MDTs is a drawback. Bearing in mind the growing trend in Europe towards tumour-based specialisation and concentration of services for complex cancer treatments, efforts should be made to define the critical elements of MDT models, elucidate their specific 
advantages and outline what resources are needed for implementation.

\section{Role of the funding source}

This work was supported by EPAAC and Carlos III Institute of Health Research (Instituto de Salud Carlos III - ISCIII) in the form of research grants to the Cancer Research Network (RD 12/0036/0053), which provided financial support for the conduct of the research. The funders had no role in the study design, data collection and analysis.

\section{Conflicts of interest}

None to declare.

\section{Acknowledgements}

We should like to acknowledge the support received from the Carlos III Institute of Health Research. This project was undertaken within the framework of the European Partnership for Action Against Cancer (EPAAC). We are most grateful for the help received from Saskia Van den Bogaert (Federal public service health, food chain safety and environment, Belgium) in preparing the work.

\section{References}

[1] Haward R. Organizing a comprehensive framework for cancer control. In: Coleman MP, Alexe D-M, Albreht T, McKee M, editors. Responding to the challenge of cancer care in Europe. Ljubljana: Institute of Public Health of the Republic of Slovenia and European Observatory on Health Systems and Policies (EOHSP); 2008. p. 113-34.

[2] Gouveia J, Coleman MP, Haward R, Zanetti R, Hakama M, Borras JM, et al. Improving cancer control in the European Union: conclusion from the Lisbon roundtable under the Portuguese EU presidency (2007). European Journal of Cancer 2008;44:1457-62.

[3] Atun R, Ogawa T, Martin-Moreno JM. Analysis of national cancer control programmes in Europe. London: Imperial College London; 2009.

[4] Jelenc M, van Hoof E, Albreht T, Meglič M, Seljak M, Krnel SR. Joint action European partnership for action against cancer. Archives of Public Health 2012;70:24.

[5] European Commission Communication from the Commission on Action Against Cancer: European Partnership. COM(2009) 291/4; 2009. Available from: 〈http://ec.europa.eu/health/ph_information/ dissemination/diseases/docs/com_2009_291.en.pdf).

[6] Saini KS, Taylor C, Ramirez AJ, Palmieri C, Gunnarsson U, Schmoll $\mathrm{HJ}$, et al. Role of the multidisciplinary team in breast cancer management: results from a large international survey involving 39 countries. Annals of Oncology 2012;23:853-9.

[7] Ruhstaller T, Roe H, Thürlimann B, Nicoll JJ. The multidisciplinary meeting: an indispensable aid to communication between different specialities. European Journal of Cancer 2006;42:2459-62.

[8] Crawford R, Greenberg D. Improvements in survival of gynaecological cancer in the Anglia region of England: are these an effect of centralisation of care and use of multidisciplinary management. BJOG 2012;119:160-5.

[9] van Heek NT, Kuhlmann KF, Scholten RJ, de Castro SM, Busch OR, van Gulik TM, et al. Hospital volume and mortality after pancreatic resection: a systematic review and an evaluation of intervention in the Netherlands. Annals of Surgery 2005;242:781-8.

[10] Forshaw MJ, Gossage JA, Stephens J, Strauss D, Botha AJ, Atkinson S, et al. Centralisation of oesophagogastric cancer services: can specialist units deliver. Annals of the Royal College of Surgeons of England 2006;88:566-70.
[11] Al-Sarira AA, David G, Willmott S, Deakin M, Corless DJ, Slavin JP Oesophagectomy practice and outcomes in England. British Journal of Surgery 2007;94:585-91.

[12] Wright FC, Vito C, Langer B, Hunter A. Expert panel on multidisciplinary cancer conference standards, multidisciplinary cance conferences: a systematic review and development of practice standards. European Journal of Cancer 2007;43:1002-10.

[13] Borras JM, Albreht T, Audisio R, Briers E, Casali P, Esperou H, et al. Policy statement on multidisciplinary cancer care: European Partnership for Action Against Cancer Consensus Group. European Journa of Cancer 2014;50(3):475-80.

[14] Kurpad R, Kim W, Rathmell WK, Godley P, Whang Y, Fielding J, et al. A multidisciplinary approach to the management of urologic malignancies: does it influence diagnostic and treatment decisions. Urologic Oncology 2011;29:378-82.

[15] Segelman J, Singnomklao T, Hellborg H, Martling A. Differences in multidisciplinary team assessment and treatment between patients with stage IV colon and rectal cancer. Colorectal Disease 2009; $11: 768-74$

[16] Pawlik TM, Laheru D, Hruban RH, Coleman J, Wolfgang CL, Campbell $\mathrm{K}$, et al. Evaluating the impact of a single-day multidisciplinary clinic on the management of pancreatic cancer. Annals of Surgica Oncology 2008; 15:2081-8.

[17] Lordan JT, Karanjia ND, Quiney N, Fawcett WJ, Worthington TR. A 10 -year study of outcome following hepatic resection for colorectal liver metastases - The effect of evaluation in a multidisciplinary team setting. European Journal of Surgical Oncology 2009;35:302-6.

[18] Chekerov R, Denkert C, Boehmer D, Suesse A, Widing A, Ruhmland $\mathrm{B}$, et al. Online tumor conference in the clinical management of gynecological cancer: experience from a pilot study in Germany. International Journal of Gynecological Cancer 2008;18:1-7.

[19] Davies AR, Deans DA, Penman I, Plevris JN, Fletcher J, Wall L, et al. The multidisciplinary team meeting improves staging accuracy and treatment selection for gastro-esophageal cancer. Diseases of the Esophagus 2006;19:496-503.

[20] Newman EA, Guest AB, Helvie MA, Roubidoux MA, Chang AE, Kleer CG, et al. Changes in surgical management resulting from case review at a breast cancer multidisciplinary tumor board. Cancer 2006;107:2346-51

[21] Stephens MR, Lewis WG, Brewster AE, Lord I, Blackshaw GR, Hodzovic I, et al. Multidisciplinary team management is associated with improved outcomes after surgery for esophageal cancer. Diseases of the Esophagus 2006;19:164-71

[22] Burton S, Brown G, Daniels IR, Norman AR, Mason B, Cunningham D. MRI directed multidisciplinary team preoperative treatment strategy: the way to eliminate positive circumferential margins. British Journal of Cancer 2006;94:351-7.

[23] Nguyen NP, Vos P, Lee H, Borok TL, Karlsson U, Martinez T, et al. Impact of tumor board recommendations on treatment outcome for locally advanced head and neck cancer. Oncology 2008;75:186-91.

[24] Ibrahim T, Flamini E, Fabbri L, Serra P, Mercatali L, Ricci R et al. Multidisciplinary approach to the treatment of bone metastases: Osteo-Oncology Center, a new organisational model. Tumori 2009;95:291-7

[25] Santillan AA, Messina JL, Marzban SS, Crespo G, Sondak VK. Pathology review of thin melanoma and melanoma in situ in a multidisciplinary melanoma clinic: impact on treatment decisions. Journal of Clinica Oncology 2010;28:481-6.

[26] Sooriakumaran P, Dick JA, Thompson AC, Morley R. The central urology multidisciplinary team-is it time to change the referral criteria? An audit of practice in a district general hospital in London. Urology 2009;91:700-2

[27] Pituskin E, Fairchild A, Dutka J, Gagnon L, Driga A, Tachynski P et al. Multidisciplinary team contributions within a dedicated outpatient palliative radiotherapy clinic: a prospective descriptive study International Journal of Radiation Oncology, Biology and Physics 2010;78:527-32

[28] Du CZ, Li J, Cai Y, Sun YS, Xue WC, Gu J. Effect of multidisciplinary team treatment on outcomes of patients with gastrointestinal malignancy. World Journal of Gastroenterology 2011;17:2013-8

[29] Friedland PL, Bozic B, Dejar J, Kuan R, Meyer C, Phillips M. Impact of multidisciplinary team management in head and neck cancer patients. British Journal of Cancer 2011;104:1246-8.

[30] Bydder S, Nowak A, Marion K, Phillips M, Atun R. The impact of case discussion at a multidisciplinary team meeting on the treatment and survival of patients with inoperable non-small cell lung cancer. Internal Medicine Journal 2009;39:838-48.

[31] Caudron A, Chaby G, Dadban A, Andrejak C, Dhaille F, Bagot M et al. Multidisciplinary team meetings in Oncology: first analysis of 
benefits and evaluation of activity in a Dermatology unit in France. European Journal of Dermatology 2010;20:778-84.

[32] Boxer MM, Vinod SK, Shafiq J, Duggan KJ. Do multidisciplinary meetings make a difference in the management of lung cancer. Cancer 2011:117:5112-20.

[33] Wheless SA, McKinney KA, Zanation AM. A prospective study of the clinical impact of a multidisciplinary head and neck cancer tumor board. Otolaryngology-Head and Neck Surgery 2010;143:650-4.

[34] Field KM, Rosenthal MA, Dimou J, Flet M, Gibbs P, Drummond K. Communication in and clinician satisfaction with multidisciplinary team meetings in neuro-oncology. Journal of Clinical Neuroscience 2010;17:1130-5.

[35] Freeman RK, Van Woerkom JM, Vyverberg A, Ascioti AJ. The effect of a multidisciplinary thoracic malignancy conference on the treatment of patients with esophageal cancer. The Annals of Thoracic Surgery 2011;92:1239-42.

[36] Palmer G, Martling A, Cedermark B, Holm T. Preoperative tumour staging with multidisciplinary team assessment improves the outcome in locally advanced primary rectal cancer. Colorectal Disease 2011;13:1361-9.

[37] Greer HO, Frederick PJ, Falls NM, Tapley EB, Samples KL, Kimball $\mathrm{KJ}$, et al. Impact of a weekly multidisciplinary tumor board conference on the management of women with gynecologic malignancies. International Journal of Gynecological Cancer 2010;20:1321-5.

[38] Bjegovich-Weidman M, Haid M, Kumar S, Huibregtse C, McDonald Krishnan S. Establishing a community-based lung cancer multidisciplinary clinic as part of a large integrated health care system: aurora health care. Journal of Oncology Practice 2010;6:e27-30.

[39] Kesson EM, Allardice GM, George WD, Burns HJ, Morrison DS. Effects of multidisciplinary team working on breast cancer survival: retrospective, comparative, interventional cohort study of 13722 women. British Medical Journal 2012;344:e2718.

[40] Levine RA, Chawla B, Bergeron S, Wasvary H. Multidisciplinary management of colorectal cancer enhances access to multimodal therapy and compliance with National Comprehensive Cancer Network (NCCN) guidelines. International Journal of Colorectal Disease 2012;27:1531-8.

[41] Wang YH, Kung PT, Tsai WC, Tai CJ, Liu SA, Tsai MH. Effects of multidisciplinary care on the survival of patients with oral cavity cancer in Taiwan. Oral Oncology 2012;48:803-10.

[42] Korman H, Lanni T, Shah C, Parslow J, Tull J, Ghilezan M, et al. Impact of a prostate multidisciplinary clinic program on patient treatment decisions and on adherence to NCCN Guidelines: The William Beaumont Hospital Experience. American Journal of Clinical Oncology 2012;36:121-5

[43] Catt S, Fallowfield L, Jenkins V, Langridge C, Cox A. The informational roles and psychological health of members of 10 oncology multidisciplinary teams in the UK. British Journal of Cancer 2005;93:1092-7.

[44] McNair AG, Choh CT, Metcalfe C, Littlejohns D, Barham CP, Hollowood A, et al. Maximising recruitment into randomised controlled trials: the role of multidisciplinary cancer teams. European Journal of Cancer 2008;44:2623-6

[45] Harrison JD, Choy ET, Spillane A, Butow P, Young JM, Evans A. Australian breast cancer specialists' involvement in multidisciplinary treatment planning meetings. Breast 2008;17:335-40.

[46] Lanceley A, Savage J, Menon U, Jacobs I. Influences on multidisciplinary team decision-making. International Journal of Gynecological Cancer 2008;18:215-22.

[47] Soukop M, Robinson A, Soukop D, Ingham-Clark CL, Kelly MJ. Results of a survey of the role of multidisciplinary team coordinators for colorectal cancer in England and Wales. Colorectal Disease 2007; 9:146-50

[48] Choy ET, Chiu A, Butow P, Young J, Spillane A. A pilot study to evaluate the impact of involving breast cancer patients in the multidisciplinary discussion of their disease and treatment plan. Breast 2007; $16: 178-89$

[49] Chirgwin J, Craike M, Gray C, Watty K, Mileshkin L, Livingston PM. Does multidisciplinary care enhance the management of advanced breast cancer? Evaluation of advanced breast cancer multidisciplinary meetings. Journal of Oncology Practice 2010;6:294-300.

[50] Scher KS, Tisnado DM, Rose DE, Adams JL, Ko CY, Malin JL, et al. Physician and practice characteristics influencing tumor board attendance: results from the provider survey of the Los Angeles Women's Health Study. Journal of Oncology Practice 2011;7:103-10.

[51] Prades J, Borras JM. Multidisciplinary cancer care in Spain, or when the function creates the organ. BMC Public Health 2011;11:141.

[52] Wilcoxon H, Luxford K, Saunders C, Peterson J, Zorbas H. Multidisciplinary cancer care in Australia: a national audit highlights the gaps in care and medico-legal implications. Asia-Pacific Journal of Clinical Oncology 2011;7:34-40.

[53] Magnani T, Valdagni R, Salvioni R, Villa S, Bellardita L, Donegani S, et al. The 6-year attendance of a multidisciplinary prostate cancer clinic in Italy: incidence of management changes. BJU International 2012;110:998-1003

[54] Hudak JL, McLeod DG, Brassell SA, Gant DA, Shaar S, Hudak RP, et al. The design and implementation of a multidisciplinary prostate cancer clinic. Urologic Nursing 2007;27:491-8.

[55] Wiederholt PA, Connor NP, Hartig GK, Harari PM. Bridging gaps in multidisciplinary head and neck cancer care: nursing coordination and case management. International Journal of Radiation Oncology, Biology and Physics 2007;69:S88-91.

[56] Maslin-Prothero S. The role of the multidisciplinary team in recruiting to cancer clinical trials. European Journal of Cancer Care (English) 2006;15:146-54.

[57] Kuroki L, Stuckey A, Hirway P, Raker CA, Bandera CA, DiSilvestro PA, et al. Addressing clinical trials: can the multidisciplinary tumor board improve participation? A study from an academia women's cancer program. Gynecologic Oncology 2010;116:295-300.

[58] Sweeney E, Tapper Y. Improving support information with an integrated CNS service. Nursing Times 2006;102:28-30

[59] Knowles G, Sherwood L, Dunlop MG, Dunlop MG, Dean G, Jodrell D, et al. Developing and piloting a nurse-led model of follow-up in the multidisciplinary management of colorectal cancer. European Journal of Oncology Nursing 2007;11:212-23.

[60] Brennan ME, Butow P, Marven M, Spillane AJ, Boyle FM. Survivorship care after breast cancer treatment-experiences and preferences of Australian women. Breast 2011;20:271-7.

[61] Jefford M, Lotfi-Jam K, Baravelli C, Grogan S, Rogers M, Krishnasamy $\mathrm{M}$, et al. Development and pilot testing of a nurse-led posttreatment support package for bowel cancer survivors. Cancer Nursing 2011;34:e1-10.

[62] Hong NJL, Gagliardi AR, Bronskill SE, Paszat LF, Wright FC. Multidisciplinary cancer conferences: exploring obstacles and facilitators to their implementation. Journal of Oncology Practice 2010;6:61-8

[63] Jones L, Leach L, Chambers S, Occhipinti S. Scope of practice of the breast care nurse: a comparison of health professional perspectives. European Journal of Oncology Nursing 2010;14:322-7.

[64] Bellardita L, Donegani S, Spatuzzi AL, Valdagni R. Multidisciplinary versus one-on-one setting: a qualitative study of clinicians' perceptions of their relationship with patients with prostate cancer. Journal of Oncology Practice 2011;7:e1-5.

[65] Haward R, Amir Z, Borrill C, Dawson J, Scully J, West M, et al. Breast cancer teams: the impact of constitution, new cancer workload, and methods of operation on their effectiveness. British Journal of Cancer 2003:7:15-22.

[66] Carey M, Sanson-Fisher R, Lotfi-Jam K, Schofield P, Aranda S. Multidisciplinary care in cancer: do the current research outputs help? European Journal of Cancer Care (English) 2010;19:434-41.

[67] Tattersall MH. Multidisciplinary team meetings: where is the value. The Lancet Oncology 2006;7:886-8.

[68] Valentini V, Aristei C, Glimelius B, Minsky BD, Beets-Tan R, Borras JM, et al. Scientific Committee, Multidisciplinary Rectal Cancer Management: 2nd European Rectal Cancer Consensus Conference (EURECA-CC2). Radiotherapy and Oncology 2009;92:148-63.

[69] Department of Health (UK NHS Executive). Manual of cancer services standards. London; 2001.

[70] National Breast Cancer Centre (NBCC). Multidisciplinary meetings for cancer care: a guide for health service providers. Camperdown NSW (Australia); 2005

[71] Albreht T, McKee M, Alexe DM, Coleman M, Martin-Moreno JM. Making progress against cancer in Europe in 2008. European Journal of Cancer 2008;44:1451-6.

[72] Haward RA. Establishing cancer units. British Journal of Cancer $1995 ; 72: 531-4$ 